\title{
Corticosteroids in primary tuberculosis with bronchial obstruction
}

\author{
M Toppet, A Malfroot, M P Derde, V Toppet, M Spehl, I Dab
}

\begin{abstract}
The usefulness of prednisolone in combination with the modern potent antituberculous drugs has been studied in 29 children with primary lung tuberculosis and hilar adenopathy causing bronchial obstruction. These children were divided at random in two groups of 15 and 14 patients. Both groups were treated similarly except that one group received prednisolone. Both groups were very similar before the onset of treatment for most variables. Tuberculous infection healed in both groups but the group on steroids improved earlier and had significantly fewer complications, both on radiography and bronchoscopy. Only two of the patients on steroids still had progressive lesions: a very young baby probably because he developed two severe viral infections consecutively, and another infant of 7 months whose treatment was unreliable, as the parents were not very compliant. Some patients initially not treated with prednisolone improved only after it was given. Prednisolone treatment is not recommended when the reliability of the treatment cannot be guaranteed, as the hazard of harm would exceed the expected benefit.
\end{abstract}

Hôpital Universitaire

Des Enfants Reine

Fabiola,

Université Libre

de Bruxelles

M Toppet

Academisch Ziekenhuis

Kinderen,

Respiratory and

Cystic Fibrosis Clinic,

Paediatric Department

A Malfroot

I Dab

Biostatistics

Department,

Vrije Universiteit,

Brussel

M P Derde

Paediatric Radiology

Department,

Hôpital Universitaire

Saint Pierre Bruxelles,

Université Libre

de Bruxelles

V Toppet

M Spehl

Correspondence to:

Professor I Dab,

Respiratory and

Cystic Fibrosis Clinic,

Paediatric Department,

Academisch Ziekenhuis

Kinderen,

Vrije Universiteit

Brussel,

Laarbeeklaan 101

B-1090 Brussels,

Belgium.

Accepted 7 June 1990

Primary tuberculosis still occurs in our country, especially in people living in very poor conditions and in recent immigrant populations. ${ }^{1}$ This has also been shown recently by epidemiologists in the USA. ${ }^{1}$ In our department we have discovered about 100 new cases each year.

Children who are symptomatic for tuberculosis suffer mostly, among other complications, from hypertrophy of the hilar lymph nodes. These can compress bronchi and even disrupt and discharge their caseous content in the bronchial tree (fistulisation). ${ }^{2-6}$

There is little information about the usefulness of corticosteroids in the treatment of bronchial obstruction in primary tuberculosis and that available in recent papers ${ }^{7}$ is often from old publications. In the 1960s there were claims for its efficacy, when given at the early onset of bronchial obstruction and before fistulisation, to prevent complications such as fistulisation and bronchiectasis. ${ }^{238}$ Other authors such as Nemir et al did not confirm this beneficial effect in a preliminary study. ${ }^{9}$ This study suffered from an uneven distribution of patients, and in a later study on a larger series of children the authors demonstrated a significant and noticeable improvement in tuberculous patients treated with steroids compared with those not treated with steroids. ${ }^{10}$

Steroids are neither harmless nor easy to con- trol when needed for a prolonged period of time. Hypertension and water retention as well as potassium depletion are potential risks. Furthermore it is well known that premature and abrupt interruption of steroids is often followed by a severe 'rebound' reaction. ${ }^{3}{ }^{11}$ This can be even more severe than the initial lesion. $^{3}$

We decided to undertake a new open trial to examine the use of steroids in bronchial obstruction (i) because more efficient antituberculous drugs are now available and it was not known whether steroids had a beneficial effect when used with these newer drugs and (ii) because of the controversy concerning the risks surrounding steroid use. The study was restricted to patients with primary tuberculosis and bronchial obstruction without fistulisation as we wanted to see whether fistulisation could be avoided by steroid treatment.

\section{Patients and methods}

A total of 29 patients ( 26 from immigrant families) were treated for symptomatic tuberculosis with severe bronchial obstruction suspected by radiology and demonstrated by bronchoscopy. Their ages ranged from 4 months to 15 years (median $7 \cdot 8$ ). There were 10 girls and 19 boys. demiological figures. ${ }^{1}$

The diagnosis was established in all patients through a recent tuberculin conversion, using 2 IU of Rt 23 tuberculin, from the Statens Serum Institut of Copenhagen, injected intradermally. This test was positive in all subjects-that is, an induration of at least $10 \mathrm{~mm}$ after 48 or 72 hours. In 14 patients tuberculin tests were performed because of clinical signs such as an unexpected course of pulmonary consolidation, long standing unexplained fever or cough, and in nine patients because of a recent positive family history of tuberculosis. Only in six patients was severe primary tuberculosis diagnosed through a routine and systematical tracing at school.

Chest radiographs were available for all patients before treatment and in 23 at one, two, three, six, nine, and 12 months after starting the treatment. The radiological findings were arbitrarily codified to measure objectively and uniformly the extent of the pulmonary involvement. The size of the adenopathy was scored from 1 to 3 , segmental consolidation or hyperinflation scored 1, lobar consolidation or hyperinflation scored 3 , and pulmonary consolidation or hyperinflation scored 6 . These scores were added up to obtain the total radiological 
score. All radiographs were read 'blind' separately by the two paediatric radiologists (MS and VT).

Bronchoscopy was also performed blind by the two paediatric respiratory physicians (ID and $\mathrm{AM}$ ) on all patients with abnormal radiological findings. Rigid bronchoscopy (bronchoscopes with Johns Hopkins telescopes, Storz Germany) was performed under general anaesthesia for patients younger than 5, and flexible fiberoptic bronchoscopy (BF 3 C 10 and BF P 10, Olympus Japan) was performed in the older patients under local anaesthesia. Bronchoscopy findings were scored depending on the localisation and the extent of the compression as shown in table 1. Patients who already had bronchial fistulisation were not included in this study as the aim was to verify whether fistulisation could be prevented. Patients with meningitis, or miliary tuberculosis, were also excluded. Patients without clinical and radiological abnormalities and negative bacteriology for Mycobacterium tuberculosis did not need bronchoscopy and were not eligible for the study. Only those 29 patients with a compression of at least $50 \%$ of a bronchus and with a bronchoscopy score (see table 1) equal or higher than 2 have been selected for this trial. The endoscopy was repeated at least after one or two months of treatment in all of them and, when the course was unfavourable, even more often.

Antituberculous treatment consisted of a combination of isoniazid ( $10 \mathrm{mg} / \mathrm{kg}$ body weight/day to a maximum $300 \mathrm{mg} /$ day) and rifampicin (15 mg/kg body weight to a maximum $600 \mathrm{mg} /$ day) for one year and ethambutol for two months (20 mg/kg body weight/day) providing there was no visual disturbance.

Table 1 Bronchoscopy score

\begin{tabular}{ll}
\hline & Score \\
\hline (A) Localisation: & 4 \\
Trachea & 3 \\
Main bronchus & 2 \\
Lobar bronchus & 1 \\
Segmental bronchus & \\
(B) Importance of the obstruction: & 4 \\
Total or $>75 \%$ & 2 \\
$50-75 \%$ & 1 \\
$<50 \%$ & 0 \\
No obstruction & \\
\hline The bronchoscopy score $=\Sigma(\mathrm{A} \times \mathrm{B})$. &
\end{tabular}

Treatment was systematically adjusted whenever there was a positive culture and when sensitivity testing in vitro showed that the previous choice was not appropriate.

Patients were divided into group 1 (steroid treatment) or group 2 (no steroid treatment) by previously randomised and numbered envelopes.

\section{STEROID TREATMENT}

Prednisolone was started at a daily dose of 2 $\mathrm{mg} / \mathrm{kg}$ of body weight for 15 days and was progressively decreased to be stopped between 2.5 and 3 months. We had previously observed that within a few days of too early or abrupt an interruption of steroids patients often showed a severe rebound reaction. Sometimes there were even more extensive lesions than before the onset of prednisolone and the hazard of fistulisation had also increased.

Paediatric endocrinologists recommended that these children receiving such high doses of corticosteroids for more than one month should have a sodium restricted diet and that they should also receive potassium gluconate supplements and gastric protection by aluminium phosphate.

\section{FOLLOW UP}

A few children were admitted to hospital before the start of the trial for either bronchoscopy under general anaesthesia or because of their poor general condition. All drugs were taken orally. To guarantee optimal therapeutic compliance, which was essential in the steroid group where side effects due to incorrect diet could be dangerous, and to ensure that patients were seen as scheduled, a special home care unit was set up by MT. $^{12}$

\section{GROUP 1 (STEROIDS)}

This group comprised 15 children (11 boys, four girls) aged 4 months to 12 years (median 6.3 years). Two were lost to follow up after six months (table 2).

\section{GROUP 2 (NO STEROIDS)}

This group comprised 14 children (eight boys, six girls) aged 18 months to 15 years (median

Table 2 Characteristics of the patients treated with steroids (group 1)

\begin{tabular}{|c|c|c|c|c|c|c|}
\hline $\begin{array}{l}\text { Case } \\
\text { No }\end{array}$ & $\begin{array}{l}\text { Age } \\
\text { (years) }\end{array}$ & $\begin{array}{l}\text { Mycobacterium } \\
\text { tuberculosis }\end{array}$ & $\begin{array}{l}\text { Extra } \\
\text { lesions at onset } \\
\text { seen on } \\
\text { radiology }\end{array}$ & $\begin{array}{l}\text { Score on } \\
\text { radiology }\end{array}$ & $\begin{array}{l}\text { Score on } \\
\text { bronchoscopy }\end{array}$ & Comments \\
\hline $\begin{array}{l}1 \\
2 \\
3 \\
4 \\
5 \\
6 \\
7\end{array}$ & $\begin{array}{r}10 \cdot 0 \\
4 \cdot 0 \\
1 \cdot 8 \\
1 \cdot 5 \\
1 \cdot 5 \\
7 \cdot 0 \\
0 \cdot 3\end{array}$ & $\begin{array}{l}+ \\
+ \\
+ \\
+ \\
+ \\
+ \\
+\end{array}$ & $\begin{array}{l}\text { Lobar consolidation } \\
\text { Segmental hypoventilation } \\
\text { Lobar consolidation } \\
\text { Segmental consolidation } \\
\text { Multiple consolidation }\end{array}$ & $\begin{array}{r}3 \\
3 \\
4 \\
3 \\
5 \\
3 \\
10\end{array}$ & $\begin{array}{r}17 \\
16 \\
26 \\
2 \\
10 \\
4 \\
16\end{array}$ & $\begin{array}{l}\text { Measles, respiratory syncytial virus } \\
\text { infection, fistulisation }\end{array}$ \\
\hline $\begin{array}{l}8 \\
9 \\
10 \\
11 \\
12 \\
13 \\
14 \\
15\end{array}$ & $\begin{array}{r}12 \cdot 0 \\
8 \cdot 0 \\
0 \cdot 8 \\
0 \cdot 3 \\
0 \cdot 6 \\
4 \cdot 0 \\
11 \cdot 0 \\
2 \cdot 0\end{array}$ & $\begin{array}{l}+ \\
- \\
- \\
+ \\
- \\
- \\
+\end{array}$ & $\begin{array}{l}\text { Lobar consolidation } \\
\text { Pulmonary hypoventilation } \\
\text { Lobar consolidation } \\
\text { Segmental hypoventilation } \\
\text { Segmental consolidation } \\
\text { Lobar consolidation } \\
\text { Segmental consolidation }\end{array}$ & $\begin{array}{l}6 \\
9 \\
6 \\
4 \\
3 \\
3 \\
6 \\
6\end{array}$ & $\begin{array}{l}24 \\
26 \\
15 \\
15 \\
12 \\
16 \\
18 \\
14\end{array}$ & $\begin{array}{l}\text { Lost to follow up after } 2 \text { months } \\
\text { Bad compliance, fistulisation }\end{array}$ \\
\hline
\end{tabular}


Table 3 Characteristics of the patients treated without steroids (group 2)

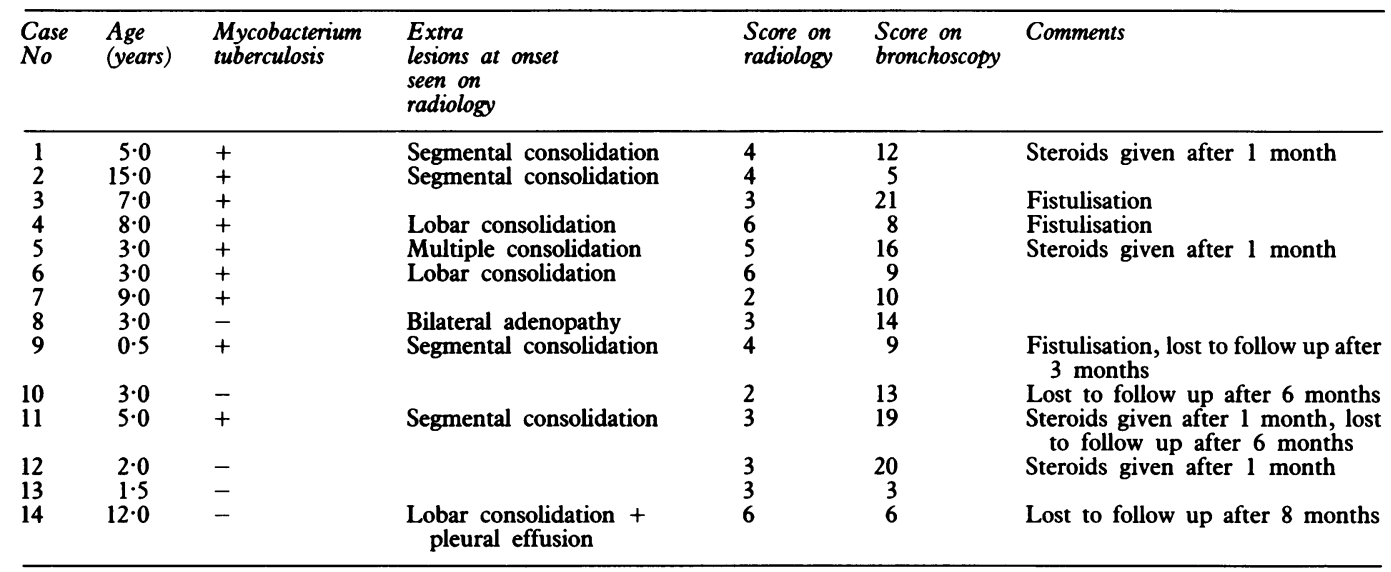

8.3 years). Ten had a regular follow up in our home care clinic; four were followed up elsewhere or left the country and their data were incomplete and not used for statistical analysis (table 3).

\section{STATISTICAL ANALYSIS}

Statistics were performed by MPD. All tests were carried out two tailed at the $5 \%$ level of significance. The Mann-Whitney test was used to evaluate the similarity between the two treatment groups at the start of the study and to compare the change of the variables during treatment in both groups. The course of the variables within each of the groups was investigated by the Wilcoxon test. In order to compare the number of patients showing an improvement on radiology in both groups, Fisher's exact test was used.

\section{ETHICAL COMMITTEE}

The ethical committee did not consent for double blind study because:

(1) Before the trial corticosteroids were used routinely in all patients with bronchial obstruction in primary tuberculosis and therefore patients without steroids should be known and given the possibility to interrupt the trial in case of their condition deteriorating.

(2) Patients taking corticosteroids should have sodium restricted, potassium enriched diets and patients without steroids should not.

\section{Results}

Tables 2 and 3 illustrate the characteristics and course of the children in the two groups.

\section{RADIOLOGY (TABLE 4)}

Because of incomplete radiological follow up over the planned treatment period, and despite complete bronchoscopic follow up during the first months of the study, information on six of the original 29 patients was not sufficient for statistical analysis (two in group 1, four in group 2, not significant by Fisher's exact test). Radiological follow up over 12 months was available for the remaining 23 patients. After
Table 4 Course of radiological score

\begin{tabular}{lll}
\hline & $\begin{array}{l}\text { Group 1 } \\
\text { (steroids) }\end{array}$ & $\begin{array}{l}\text { Group 2 } \\
\text { (no steroids) }\end{array}$ \\
\hline No of subjects & 13 & 10 \\
Improvement seen $\leqslant 1$ month & 7 & 0 \\
Normalisation seen: & 6 & $(1)^{*}$ \\
53 Months & 3 & $(2)^{*}$ \\
Between 3 and 6 months & 4 & 6 \\
$\quad$ Between 6 and 12 months & 2 & 5 \\
Deterioration during treatment & 0 & 1
\end{tabular}

${ }^{*}$ After the addition of steroids for the appearance of lobar consolidation and increased score on bronchoscopy.

one month of treatment the number of improved radiographs was significantly higher in group $1(7 / 13)$ than in group $2(0 / 10)$ $(p=0.0075$ by Fisher's exact test). Normalisation after three months was significantly higher in group $1(7 / 13)$ than in group $2(0 / 9)(p=0.04)$. One child in group 2 who became normal was given steroids one month after the onset of treatment and he was not included in the statistical evaluation in any group.

BRONCHOSCOPY (TABLE 5)

Information was available for all 29 patients after one month of treatment. Bronchoscopy scores decreased significantly in both groups (respectively $\mathrm{p}=0.0007$ and $\mathrm{p}=0.003$ for group 1 and for group 2 on the Wilcoxon test). A comparison of the grade of the change by means of the Mann-Whitney test, however, indicated a more important decline in group 1 than in group $2(p=0.003)$.

Some data are worth mentioning, though not clearly represented on the tables and not used for statistical evaluations, are that three children from group 2 (cases $3,4,9$ ) developed fistulas and granulomas within one month and needed several bronchoscopies and extraction with forceps before the airways became completely clear again. Four children (cases 1, 5, 11, 12) who were randomised in group 2, worsened on both evidence from the radiographs and bronchoscopy despite one month of correct antituberculous treatment and eventually corticosteroids were added to their treatment. They then improved but to avoid any bias they were not included for statistical evaluation in group 1 . In group 1 one patient (case 12), known for his poor therapeutic compliance, developed a 
Table 5 Course of bronchoscopy score

\begin{tabular}{|c|c|c|c|c|c|}
\hline & \multicolumn{2}{|l|}{ Group 1 (steroids) } & \multicolumn{3}{|c|}{ Group 2 (no steroids) } \\
\hline & Before treatment & $\begin{array}{l}\text { After I month } \\
\text { treatment }\end{array}$ & Before treatment & & $\begin{array}{l}\text { After } 1 \text { month } \\
\text { treatment }\end{array}$ \\
\hline $\begin{array}{l}\text { Mean (SD) } \\
\text { Mean (SD) difference } \\
\text { Wilcoxon }\end{array}$ & $14 \cdot 7(7 \cdot 3)$ & $\begin{array}{l}12 \cdot 1(6.9)^{2 \cdot 7(3.9)} \\
\mathrm{p}=0.0007\end{array}$ & $11 \cdot 8(5 \cdot 7)$ & $\begin{array}{c}5.9(5) \\
p=0.003\end{array}$ & $5 \cdot 9(6 \cdot 5)$ \\
\hline
\end{tabular}

bronchial fistula after three months. Another patient from the same group (case 7), who developed successively measles and respiratory syncytial virus infections at the fourth month after the start of the treatment, then showed bronchial fistulisation, despite perfect therapeutic compliance. In fact these two children showed fistulisation after the end of the steroid treatment and not during it.

The number of children who needed more than two bronchoscopies was appreciably higher in the group not taking steroids than in the steroid group (six patients compared with one).

\section{Discussion}

In our department most of the children with primary tuberculosis come from a high risk group. They are mostly immigrant families, originating from underdeveloped countries, though the infection often takes place in our country because of bad housing and working conditions. This accounts for the very high rate of 18 positive cultures for $M$ tuberculosis on these 29 patients and is also representative of the severity of the clinical symptoms and radiological abnormalities at the onset of the diagnosis.

The relatively small number of drop outs, despite the fact that many families could not express themselves in one of the local languages, can be attributed to the home care structure stimulating trust and enabling a close and correct drug monitoring. ${ }^{12}$

There is a relatively clear agreement on how to use the different specific antituberculous drugs in monotherapy or in combination, depending on the clinical picture. ${ }^{45713}$ The aim of our study was not to re-evaluate this and anyway all our patients were cured of their infection, whether steroids were added or not. Our goal was limited to the examination of the effect of prednisolone on bronchial compression by lymph nodes before the disruption occurred. Nemir et al also showed an effect on the course after fistulisation, ${ }^{10}$ but we preferred not to include the latter in order to have a homogeneous series needing fewer patients.

The beneficial effect of corticosteroids in combination with antituberculous drugs is well known in important pleural effusion. ${ }^{3-5}$

Adding corticosteroids in the first three months of antituberculous treatment has also been studied in adults with advanced cavitary pulmonary tuberculosis, and showed a favourable influence on radiological and clinical course and on pulmonary function. ${ }^{11}$ Despite older and less active tuberculostatics these patients did not run a greater risk.

As stressed in the introduction, little informa- tion is available about the usefulness of corticosteroids in childhood primary tuberculosis, and we were not able to find any recent study. Nemir et al in 1963 were not capable of demonstrating any benefit on a small series of children. ${ }^{9}$ These authors concluded that the steroid group suffered more severe lesions than the group not on steroids as was clearly shown in the significantly larger number of patients positive for $M$ tuberculosis in the group on steroids: 'In general, the prednisone-treated group was more severely ill as judged by the greater frequency of cultures positive for tubercle bacilli, obtained chiefly before steroid therapy, and the presence of other diseases before adjunct therapy was initiated . . . . In a second study in 1967 by the same group on a larger series of children 'a higher percentage of marked improvement occurred among the steroid treated group, namely $36 \%$ compared to $15 \%$ in the control group $(\mathrm{p}<0.05) \cdot{ }^{10}$ However the steroid group suffered several side effects such as hypertension, excessive weight gain, and 'moonface'; none of these side effects was seen in our study. In 1965 Gerbeaux et al also claimed that steroids were beneficial on a very large series of children. ${ }^{23}$

Our study showed a more even distribution of the patients in two comparable samples to that of the patients reported by Nemir et al in their preliminary study. There were no significant bacteriological, radiological, or bronchoscopic differences between our two groups before the onset of any treatment (tables 2 and 3 ). The only difference was that the steroid group was slightly younger and therefore may be at a higher possible risk for complications. Otherwise the severity of the disease was similar in both groups and the beneficial effect of the steroid treatment as reflected by the different course or outcome is certainly neither coincidental, nor due to any bias.

This modest study, performed on a small number of patients, still clearly demonstrates the benefit of adding prednisolone whenever bronchial compression is demonstrated, and before airways are damaged by caseous fistulas, even though all patients were given a combination of very active antituberculous drugs including rifampicin, not used in the previous studies. Though in both groups the bronchial lesions improved significantly under treatment, it was faster and more noticeable in the steroid group. Moreover, the risk of complications known to occur on steroid treatment appeared only during uncontrollable or unexpected events, such as severe viral superinfection or poor therapeutic compliance. On the contrary, in the group not taking steroids, fistulisation occurred more often and on a few occasions previously mild 
compressions worsened and these improved only after the addition of prednisolone. Cushing's syndrome has never been seen in our patients, thanks to a thorough salt restricted diet and other precautions.

We conclude that whenever severe bronchial compression has been demonstrated, steroids remain beneficial and should be added to the specific antituberculous treatment notwithstanding the available powerful antituberculous drugs and despite the fact that this will increase the load of the treatment. The benefit was sufficiently noticeable and significant even in this small series to consider it unethical to continue the trial. All eligible patients should benefit from steroid treatment under optimal conditions.

The patient's or family's compliance should be carefully evaluated before starting steroids, as the risk of damage as a consequence of poor administration or an incorrect diet would be greater than the expected benefit. Patients with bronchial compression not receiving steroids should be carefully and closely observed, as they will perhaps need more therapeutic bronchoscopies.
1 Block AB, Rieder HL, Kelly GD, Canthen GH, Hayden CH, Snider DE. The epidemiology of tuberculosis in the United States. Implications for diagnosis and treatment. Clin Chest Med 1989;10:297-313.

2 Gerbeaux J. Tuberculose primaire de l'enfant. Paris: Edition Médicale Flammarion, 1967.

3 Gerbeaux J, Baculard A, Couvreur J. Primary tuberculosis in childhood. Am F Dis Child 1965;110:507-18.

4 Lorin M, Hsu KHK, Jacob SC. Treatment of tuberculosis in children. Pediatr Clin North Am 1983;30:333-48.

5 Starke JR. Modern approach to the diagnosis and treatment of tuberculosis in children. Pediatr Clin North Am 1988;35: $441-64$.

6 Chanoine JP, Toppet M, Dab I, et al. Unusual ventilationperfusion patterns in primary lung tuberculosis. Pediatr Pulmonol 1988;5:51-4.

7 Smith MHD. Tuberculosis in children and adolescents. Clin Chest Med 1989;10:381-95.

8 Rosenzweig DY, Stead WW. The role of tuberculosis and other forms of bronchopulmonary necrosis in the pathogenisis of bronchiectasis. Am Rev Respir Dis 1965;92: $769-85$.

9 Nemir RL, Cordona J, Lacoius A, David M. Prednisone therapy as an adjunct in the treatment of lymphnode bronchial tuberculosis in childhood. Am Rev Respir Dis 1963; 88:189-98.

10 Nemir RL, Cordona J, Vaziri F, Toledo F. Prednisone as an adjunct in the chemotherapy of lymphnode-bronchial tuberculosis in childhood: a double-blind study. II Further term observation. Am Rev Respir Dis 1967;95:402-10.

11 Johnson JR, Taylor BC, Morrissey JF, Jenne JW, McDonald FM. Corticosteroid therapy and pulmonary function. Am Rev Respir Dis 1965;92:376-91.

12 Toppet $M$. L'hospitalisation pédiatrique à domicile en belgique. L'enfant soigné au foyer. Arch Fr Pediatr 1977;34: que. L'enfa

13 Davidson PT, Le Quor H. Antituberculosis drugs. Clin Chest Med 1986;7:425-38. 